\title{
BMJ Global Health Towards universal health coverage: including undocumented migrants
}

\author{
Kristine Husøy Onarheim, ${ }^{1}$ Andrea Melberg, ${ }^{1}$ Benjamin Mason Meier, ${ }^{2}$ \\ Ingrid Miljeteig ${ }^{1}$
}

To cite: Onarheim KH, Melberg A, Meier BM, et al. Towards universal health coverage: including undocumented migrants. BMJ Glob Health 2018:3:e001031. doi:10.1136/ bmjgh-2018-001031

Handling editor Seye Abimbola

Received 28 June 2018 Revised 15 August 2018 Accepted 20 August 2018
Check for updates

\section{(C) Author(s) (or their} employer(s)) 2018. Re-use permitted under CC BY-NC. No commercial re-use. See rights and permissions. Published by BMJ.

${ }^{1}$ Department of Global Public Health and Primary Care, University of Bergen, Bergen, Norway

${ }^{2}$ Department of Public Policy, University of North Carolina at Chapel Hill, Chapel Hill, USA

Correspondence to Kristine Husøy Onarheim; kristine.onarheim@uib.no

\section{ABSTRACT}

As countries throughout the world move towards universal health coverage, the obligation to realise the right to health for undocumented migrants has often been overlooked. With unprecedented millions on the move-including refugees, asylum seekers, internally displaced persons and returnees-undocumented migrants represent a uniquely vulnerable subgroup, experiencing particular barriers to health related to their background, as well as insecure living and working conditions. Their legal status under national law often restricts access to, and affordability of, healthcare services. While striving to ensure health for all, national governments face challenging priority setting dilemmas in deciding who to include, which services to provide and how to cover out-of-pocket expenses. Building on comparative experiences in Norway, Thailand and the USA — which reflect varied approaches to achieving universal health coverage - we assess whether these national approaches provide rights-based access to affordable essential healthcare services for undocumented migrants. To meet the shared Sustainable Development Goal on universal health coverage, the right to health must be realised for all personsincluding undocumented migrants. To ensure universal health coverage in accordance with the right to health, governments must evaluate laws, regulations, policies and practices to determine whether undocumented migrants are included, to which services they have access and if these services are affordable. Achieving universal health coverage for everyone will require rights-based support for undocumented migrants.

\section{INTRODUCTION}

The WHO has declared that 'all roads lead to universal health coverage' (UHC), ${ }^{1}$ yet undocumented migrants do not travel those roads. Drawing on priority setting in national health policies and human right obligations under international law, this analysis outlines the pathways through which countries doand do not-include the health needs of these vulnerable migrant populations in Norway, Thailand and the USA. We do not aim to provide a full comparative approach, but highlight different political choices by examining national laws, regulations and policies. We argue that to make progress on
Summary box

Countries-with and without universal health coverage-face challenging priority setting dilemmas when deciding who to include, which services to provide and how to cover out-of-pocket expenses.

- Healthcare access for undocumented migrants is far from the aspirational Sustainable Development Goa on universal health coverage.

- In national health policies and their implementation, undocumented migrants often have access to fewer services and must cover larger out-of-pocket expenses.

- Norway, Thailand and the USA have taken vastly different approaches to universal health coverage, and only Thailand provides affordable essential care for undocumented migrants enrolled in a voluntary prepayment scheme.

- Where human rights obligations seek to realise universal health coverage for everyone, national policies on universal health coverage should ensure essential health needs independent of migrant status.

the path towards UHC and realise the human right to health, it is crucial that countries re-examine current approaches to providing healthcare for undocumented migrants.

There are currently over 68 million refugees, asylum seekers, internally displaced persons, returnees and other migrant populations. $^{2}$ Many international migrants are irregular(ised) or undocumented when they enter or stay in countries without necessary authorisations or documents required under national law. ${ }^{3}$ These undocumented migrants face particular barriers to accessing healthcare, as they often have limited access to informal social networks and safety nets, encounter legal barriers to care provision, and are regularly excluded from health insurance schemes and hence have to pay out-of-pocket for healthcare services. ${ }^{4}$ In acknowledging these challenges, the World Health Assembly passed a 2017 resolution on 'Promoting the health of refugees and migrants', which 
Table 1 Healthcare system, population and human rights in Norway, Thailand and the USA

\begin{tabular}{|c|c|c|c|}
\hline & USA & Thailand & Norway \\
\hline \multicolumn{4}{|l|}{ Health financing } \\
\hline Health expenditure per capita, PPP (constant 2011 int \$, 2014) & 9403 & 600 & 6347 \\
\hline Public health expenditure per total health expenditure (\%) & 48 & 78 & 85 \\
\hline \multicolumn{4}{|l|}{ Health outcomes (general population) } \\
\hline Life expectancy at birth (years) & 79 & 75 & 83 \\
\hline \multicolumn{4}{|l|}{ Population } \\
\hline General population $(000)$ & 325000 & 68000 & 5000 \\
\hline Undocumented migrants $(000)$ & 11000 & 1500 & 15 \\
\hline \multicolumn{4}{|l|}{ Status on selected human rights treaties } \\
\hline International Covenant on Economic, Social and Cultural Rights & Signatory & State party & State party \\
\hline Convention on the Rights of the Child & Signatory & State party & State party \\
\hline 1951 Refugee Convention & State party protocol & Not a party & State party \\
\hline
\end{tabular}

Data from 2014 to 2017. World Bank Data (https://data.worldbank.org) and Office of the United Nations High Commissioner for Human Rights (http://indicators.ohchr.org).

PPP, Purchasing Power Parity.

explicitly addressed undocumented migrants' health needs. ${ }^{5}$

Yet without an international roadmap for securing the health of migrants, there are considerable differences in healthcare access for undocumented migrants depending on their country of residence. These policy distinctions belie the universal promise of migrant health as a matter of human rights, with the right to health obligating states under international law to secure the 'highest attainable standard of health' for all persons in the countryregardless of citizenship. ${ }^{6}$ Although 170 countries have ratified or signed the International Covenant on Economic, Social and Cultural Rights, and other international treaties recognising health-related human rights (table 1), there is a disconnect between international obligations and national realisation of the right to health for undocumented migrants. ${ }^{6}$ Taken to the extreme, nearly all countries have adopted treaties ensuring the right to health for children-including the International Covenant on Economic, Social and Cultural Rights, the European Convention on Human Rights and the United Nations Convention on the Rights of the Child-yet undocumented children face restricted access to basic healthcare in many countries. ${ }^{7}$ Where the right to health seeks to assure that health services and systems are available, of sufficient quality and accessible to all, ${ }^{8}$ states fail to meet these rights-based obligations towards undocumented migrants when they restrict who is included, which services are provided and how affordable they are.

In seeking to prioritise migrant health under the Sustainable Development Goals (SDGs), WHO Director-General Tedros Adhanom Ghebreyesus made a forceful plea last year to the United Nations General Assembly: "we need better policies that promote migrants' right to health." ${ }^{\prime 9}$ The rights-based provision of healthcare for undocumented migrants is interconnected with national healthcare priority setting and resource allocation. Priority setting on UHC involves choices on who to include, which services to provide and how to cover out-of-pocket expenses. ${ }^{1011}$

\section{THREE COUNTRIES, THREE PATHS}

Countries have chosen different policy strategies in providing healthcare for undocumented migrants. Whereas legal asylum or refugee status may guarantee some level of assistance and recognition, ${ }^{12}$ undocumented migrants have less clearly stated legal protections and healthcare expectations. In the absence of international law, we highlight three examples where national policies are quite explicit-Norway, Thailand and the USA-but which differ in making moves towards UHC. In the absence of encompassing international studies, the three countries in this comparative case study-from different regions, levels of income and health system organisation-provide tentative conclusions on varied attributes of national UHC policy and provide a framework to formulate more detailed questions for larger comparative analyses. ${ }^{13}$ The Norwegian model was implemented in $1956,{ }^{14}$ whereas Thailand made its first steps towards UHC in $1975 .{ }^{15}$ In the USA, the state-based system (Medicaid) was expanded in 2010, but larger parts of the population still depend on private insurance. As highlighted in table 1, these countries also differ in regional context, healthcare financing, numbers of undocumented migrants and ratification of human right treaties. Our analysis does not examine all relevant differences, but focuses on policy decisions that determine UHC access for undocumented migrants: 'who should be included', 'which services are provided' and 'how costs are allocated'. 


\section{Norway}

Norway is a high-income country situated in northern Europe. It has a modest undocumented migrant population-in the European context-of approximately 15000 out of a population of about 5 million $(0.3 \%$ of population), with these migrants originating mainly from non-European countries. ${ }^{16}$ In terms of health spending, Norway was one of the largest in the world, at int $\$ 6347$ per capita, in 2014, of which $85 \%$ came from government spending. The health system is dominated by public actors and highly subsidised services, and universal coverage is assured for the general population. According to Norwegian laws and regulations, undocumented migrants are entitled to "immediate medical assistance if intervention cannot wait without risk of imminent death, permanent severe disability, serious injury or acute pain'. ${ }^{17}$ Among undocumented migrants, some subpopulations such as children and pregnant women have access to services beyond basic emergency care. Beyond these limited services, however, undocumented migrants are not members of the mandatory national health insurance scheme and have to cover the full costs of healthcare through out-of-pocket payments. ${ }^{18}$ In practice this means that undocumented migrants suffering from diabetes or moderate depression are not entitled to healthcare services and have to pay high costs (up to US\$5700) for giving birth.

\section{Thailand}

Thailand is a middle-income country in South-East Asia with a population of 68 million people, of which approximately 1.5 million are undocumented migrants from neighbouring countries (2.2\% of population). ${ }^{19}$ Health expenditure per capita, of which $78 \%$ was from public spending, was int $\$ 600$ in $2014 .^{20}$ The population is assured universal healthcare through three main insurance schemes, funded by either tripartite contribution (the Social Security Scheme funded by employees, employers and the government) or general taxation (the Civil Servant Medical Benefit Scheme and the Universal Coverage Scheme for otherwise non-covered). UHC has been gradually implemented to full UHC in 2002. ${ }^{15}$ Irregular migrants that register through a nationality verification process have been eligible since 2001 to purchase health insurance managed by the Ministry of Health. ${ }^{21}$ The scheme is comprehensive and, with the exception of some high-cost treatments (such as renal replacement therapy, treatment for psychosis and drug dependence), covers a wide range of curative and preventive care without copayment. Uninsured migrants have formal access to healthcare services, but they are required to cover all expenses when they do not have insurance. ${ }^{19}$

\section{USA}

The USA is a high-income country in North America, with a population of over 325 million, of which over 11 million are undocumented migrants from across the world (3.4\% of population). The USA has long spent the most of any country on health, reaching int $\$ 9403$ per capita in 2014 , with about $48 \%$ of the total health expenditure from government spending. ${ }^{20}$ This government spending largely provides support for vulnerable populations such as the elderly, the disabled and low-income individuals. ${ }^{22}$ Although the USA does not have a constitutional right to health, the 2010 Patient Protection and Affordable Care Act established a 'statutory right' to health, requiring that individuals obtain public or private health insurance and expanding access to healthcare for citizens and legal residents. ${ }^{23}$ Beyond legal residents, however, only 'qualified aliens' are eligible for public programmes, thereby excluding undocumented migrants. ${ }^{24}$ While undocumented women and children are sometimes entitled to more extensive services than other undocumented migrants, ${ }^{25}$ these state programmes exclude large numbers of undocumented migrants and neglect a range of healthcare services. This neglect of migrants and their health has been exacerbated by recent executive actions to limit lawful migration, hinder refugee programmes and incarcerate undocumented migrants. Private health insurance can be purchased without proof of citizenship, although economic barriers hinder many undocumented immigrants. ${ }^{26}$ Where these policies fail to secure medical care, hospitals remain obligated to provide care to all persons but only in emergency situations. ${ }^{25}$

\section{UHC FOR UNDOCUMENTED MIGRANTS}

These three case studies highlight divergent approaches to the provision of healthcare for undocumented migrants. Although these countries differ in ways that affect their path to UHC-in their health needs, demographics, health systems, financing, priorities and other concerns-comparative policy analysis provides a framework to evaluate their respective progress for undocumented migrants. Figures 1-3 illustrate a framework of each country's progress on UHC for the general population and for undocumented migrants. Three essential dimensions are highlighted: (1) population covered

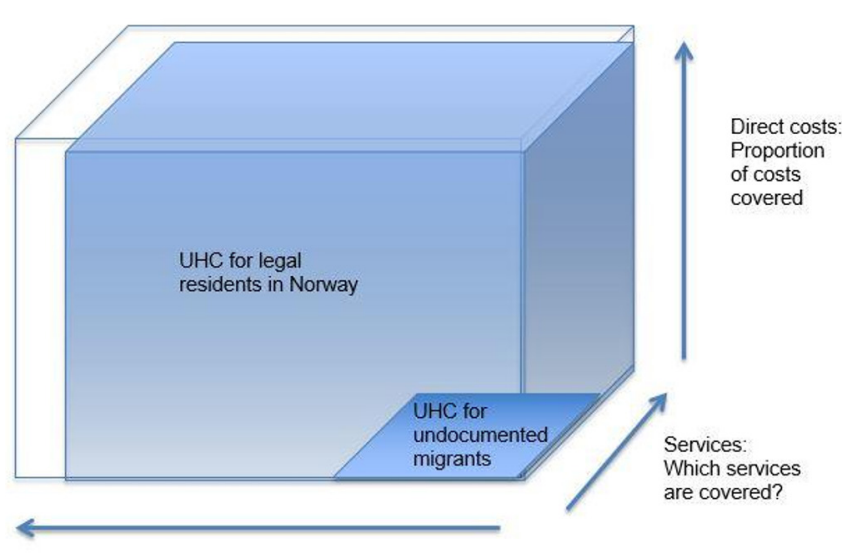

Population: Who is covered?

Figure 1 Towards universal health coverage (UHC) in Norway: coverage for the general population and undocumented migrants. 


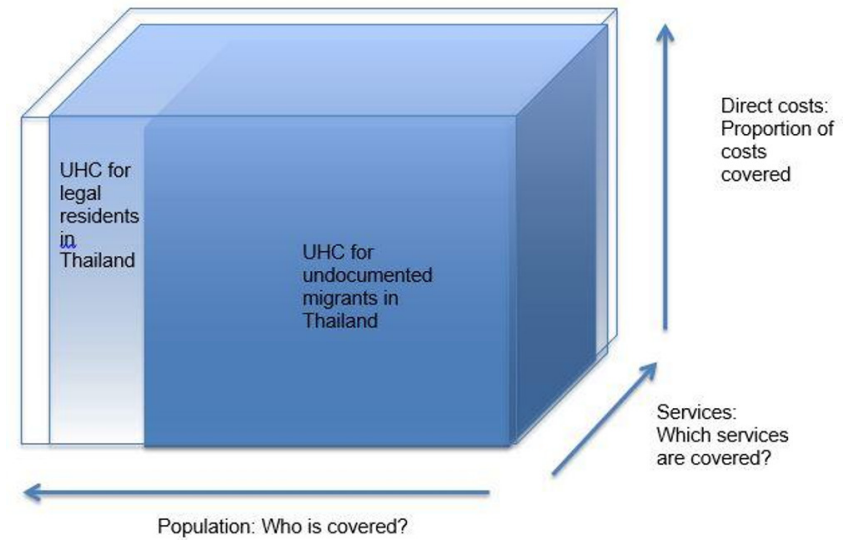

Figure 2 Towards universal health coverage (UHC) in Thailand: coverage for the general population and undocumented migrants.

(x-axis), (2) services included (z-axis) and (3) out-ofpocket costs (y-axis).

Among the three, Thailand is the only country that has set out to include everyone under its health policy, including undocumented migrants, and meet the goal of UHC for everyone to receive health coverage independent of resident status. It 'scores' high on all three axes, including all enrolled in the national insurance scheme, providing a high number of services and offering low levels of out-of-pocket expenditures for those enrolled (figure 2). More advanced services are not included in the insurance scheme, which reflects a cost-effective choice in progressively realising the right to health. Yet one might question whether excluding treatment for psychosis and drug dependence is a fair choice, as these patient groups can be considered medically worse-off. On the path to UHC, Thailand must ensure that allincluding undocumented migrants, which may have less information and resources-take part in national insurance schemes and strive to include more services in their essential healthcare package.

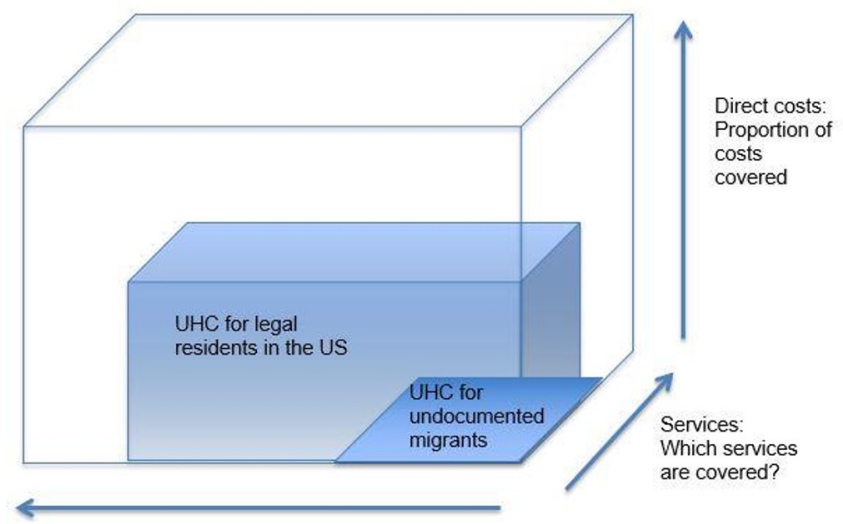

Population: Who is covered?

Figure 3 Towards universal health coverage (UHC) in the USA: coverage for the general population and undocumented migrants.
Norway provides UHC for legal residents, who are entitled to national primary and specialised healthcare services with low out-of-pocket expenses. There is a great discrepancy, however, between legal residents and undocumented migrants. Norway has restricted access for undocumented migrants to emergency care, for which costs patients have to cover themselves (figure 1). Even if undocumented migrants with the capacity to pay can get financial access to services, they are not entitled to services such as a general health practitioner. To realise UHC for everyone, in accordance with its international legal obligations under the right to health, Norway must increase the range of services provided and reduce out-of-pocket payments for undocumented migrants, in particular for essential healthcare services.

While an overwhelming majority of the populations in Thailand and Norway have free access to healthcare and where healthcare costs are largely covered by public expenses (table 1), health coverage in the USA differs substantially from the others. Where there is no UHC even for legal residents, undocumented migrants may have equally poor access to services and face similarly high healthcare costs. Yet even as national programmes ensure access to a set of core services and cover some costs for vulnerable groups, these core services are excluded to all undocumented migrants (figure 3). For the USA to progress towards UHC, a higher proportion of the population must receive access to essential health services, and efforts must be made to ensure lower out-of-pocket costs for both undocumented migrants and the larger population. While the rights-based goal of UHC sets out to provide affordable essential healthcare services for all, different starting points across countries illustrate that the next steps to progressively realise the right to health may differ based on current policies.

Realising UHC involves challenging ethical trade-offs and political questions on where best to spend national resources-to whom, for what and at what cost. ${ }^{27}$ Concerns for health, migration and financing may conflict, but policy makers should both progressively realise the right to health and allocate resources fairly and efficiently. ${ }^{28}$ In considering the health-related rights of migrants more generally, public discourses on access to services often intertwine with discussions on national borders, citizenship and security. Analysis and debates on UHC and the right to health must acknowledge that UHC, health systems and their organisation are parts of broader welfare systems. On the one hand, the fundamental aspect of a welfare state is that members both are obliged to contribute (through taxation and other contributions) as well as to receive benefits. On the other hand, it has been argued that efforts towards UHC should go beyond national citizenship. ${ }^{29}$ In this landscape, the political determinants of health and their impacts on health are often discussed ${ }^{3031}$ and illustrate how non-health concerns influence public health. This initial analysis on UHC and undocumented migrants highlights how more empirical and comparative research is needed in a larger number of countries. In looking beyond healthcare to focus 
on underlying determinants of health, policy makers must acknowledge that healthcare policies based on immigration concerns are harmful for undocumented migrants ${ }^{32}$ and further undermine efforts to reach UHC.

\section{CONCLUSION}

To meet the shared SDGs on health, everyone's right to health must be respected, protected and fulfilled. UHC and the human right to health are intertwined, and governments must be held accountable to their populations and their international obligations. In efforts to ensure UHC in accordance with the right to health, governments must evaluate laws, regulations, policies and practices to evaluate whether they meet the rights of undocumented migrants. Whereas discussions on priority setting in high-income countries often focus on new and expensive treatment, or futility of treatment for well-defined populations, our analysis has exemplified how approaches taken in Norway and the USA exclude undocumented migrants from accessing essential services. These policies and their implementation are highly problematic, undermining efforts to promote migrants' right to health. Of the three cases discussed, only one country-Thailand-is set to meet the goal on UHC for everyone. Although providing a restricted number of essential services, undocumented migrants should have access to affordable services such as vaccination and primary healthcare services. We encourage clinicians, public health experts, policy makers and researchers to scrutinise and address national policies and their implementation in reaching undocumented migrants. Priority setting towards UHC requires challenging trade-offs, but new approaches are necessary to make true the slogan 'no one left behind'. The universality of the SDGs challenges all countries to ensure that everyone-including undocumented migrants-has access to a minimum of essential and affordable healthcare services.

Contributors $\mathrm{KHO}, \mathrm{AM}$ and IM had the initial idea for the paper. $\mathrm{KHO}$ and $\mathrm{AM}$ wrote the first draft. The analysis and manuscript were developed and revised in collaboration between $\mathrm{KHO}, \mathrm{AM}, \mathrm{BMM}$ and IM. All authors read and approved the final manuscript.

Funding The authors have not declared a specific grant for this research from any funding agency in the public, commercial or not-for-profit sectors.

Competing interests $\mathrm{KHO}, \mathrm{AM}$ and IM have volunteered as medical doctors who provide care by, or in association with, a healthcare centre for undocumented migrants in Bergen, Norway. BMM has no competing interests to declare.

Patient consent Not required.

Provenance and peer review Not commissioned; externally peer reviewed.

Data sharing statement No primary data were used in the development of the paper.

Open access This is an open access article distributed in accordance with the Creative Commons Attribution Non Commercial (CC BY-NC 4.0) license, which permits others to distribute, remix, adapt, build upon this work non-commercially, and license their derivative works on different terms, provided the original work is properly cited, appropriate credit is given, any changes made indicated, and the use is non-commercial. See: http://creativecommons.org/licenses/by-nc/4.0/

\section{REFERENCES}

1. Ghebreyesus TA. All roads lead to universal health coverage. Lancet Glob Health 2017;5:e839-e840.

2. UNHCR, 2018. UNHCR statistics - Trends at a glance. Available from: http://www.unhcr.org/globaltrends2017/ [accessed 28 Jun 2018].

3. International Organization for Migration, 2018. Global migration trends factsheet. Available from: http://gmdac.iom.int/globalmigration-trends-factsheet [accessed 15 Feb 2018].

4. Avato J, Koettl J, Sabates-Wheeler R. Social Security regimes, global estimates, and good practices: the status of social protection for international migrants. World Dev 2010;38:455-66.

5. World Health Organization. Promoting the health of refugees and migrants. Draft framework of priorities and guiding principles to promote the health of refugees and migrants. Report by the Secretariat. Geneva: World Health Organization, 2017.

6. International Organization for Migration, World Health Organisation, Office of the High Commissioner for Human Rights. International Migration: Health and Human Rights, 2009.

7. Ruiz-Casares M, Rousseau C, Derluyn I, et al. Right and access to healthcare for undocumented children: addressing the gap between international conventions and disparate implementations in North America and Europe. Soc Sci Med 2010;70:329-36.

8. Gostin LO, Meier BM. The origins of human rights in global health. In: Human rights in global health: rights-based governance in a globalizing world. New York: Oxford University Press, 2018.

9. World Health Organization, 2017. Side event at the 72nd United Nations General Assembly: 'Promoting migrant health - striving for peace and decent life for all'. Available from: http://www.who.int/ migrants/news-events/en/\#wha70 [accessed 10 Mar 2018].

10. World Health Organization. The World Health Report 2010: Health systems financing: the path to universal coverage. Geneva: World Health Organization, 2010.

11. World Health Organization. Making fair choices on the path to universal health coverage: final report of the WHO consultative group on equity and universal health coverage. Geneva: World Health Organization, 2014.

12. Janmyr M, Mourad L, 2018. Millions of Syrians' lives depend on whether they're designated as 'refugees': Washington Post. Available from: https://www.washingtonpost.com/news/monkeycage/wp/2018/03/06/why-it-matters-what-we-call-syrian-refugees/? utm_term=.f8ad38b09564 [accessed 10 Mar 2018].

13. George AL, Bennett A. Case studies and theory development in the social sciences. Cambridge, MA: MIT Press, 2005.

14. Evang K. Health services in Norway. In: English version by Dorothy Burton Skårdal. 23. 3rd edn. Oslo: Norwegian Joint Committee on International Social Policy, 1970.

15. Tangcharoensathien V, Witthayapipopsakul W, Panichkriangkrai W, et al. Health systems development in Thailand: a solid platform for successful implementation of universal health coverage. Lancet 2018;391:1205-23.

16. Zhang L-C. Developing methods for determining the number of unauthorized foreigners in Norway: Statistisk sentralbyrå, 2008.

17. Forskrift om rett til helse- og omsorgstjenester til personer uten fast opphold i riket 2011.

18. Melberg A, Onarheim KH, Spjeldnæs AO. Towards universal health coverage for undocumented migrants? The Journal of the Norwegian Medical Association 2018;1.

19. Suphanchaimat R, Putthasri W, Prakongsai P, et al. Evolution and complexity of government policies to protect the health of undocumented/illegal migrants in Thailand - the unsolved challenges. Risk Manag Healthc Policy 2017;10:49-62.

20. World Bank. World bank open data, 2017. Available from: http:// data.worldbank.org/

21. Tangcharoensathien V, Thwin AA, Patcharanarumol W. Implementing health insurance for migrants, Thailand. Bull World Health Organ 2017;95:146-51.

22. Rosenbaum S. Realigning the Social Order: The Patient Protection and Affordable Care Act and the U.S. Health Insurance System. Journal of Health \& Biomedical Law 2011;7.

23. Meier BM, Gable L. US efforts to realise the right to health through the patient protection and affordable care act. Human Rights Law Review 2013;13:167-90.

24. Kinney ED. Realizing the international human right to health for noncitizens in the United States. Notre Dame Journal of International, Comparative \& Human Rights Law 2011.

25. Beck TL, Le T-K, Henry-Okafor Q, et al. Medical care for undocumented immigrants. Prim Care 2017;44:e1-e13.

26. Joseph TD. What health care reform means for immigrants: comparing the affordable care act and massachusetts health reforms. J Health Polit Policy Law 2016;41:101-16. 
27. Norheim OF. Ethical priority setting for universal health coverage: challenges in deciding upon fair distribution of health services. BMC Med 2016;14:75.

28. Rumbold B, Baker R, Ferraz O, et al. Universal health coverage, priority setting, and the human right to health. Lancet 2017;390:712-4.

29. Guinto RL, Curran UZ, Suphanchaimat R, et al. Universal health coverage in 'One ASEAN': are migrants included? Glob Health Action 2015;8:25749.
30. Mackenbach JP. Political determinants of health. Eur J Public Health 2014;24:2.

31. Ottersen OP, Frenk J, Horton R. The Lancet-University of Oslo Commission on Global Governance for Health, in collaboration with the Harvard Global Health Institute. Lancet 2011;378:1612-3.

32. Martinez O, Wu E, Sandfort T, et al. Evaluating the impact of immigration policies on health status among undocumented immigrants: a systematic review. J Immigr Minor Health 2015;17:947-70. 